\title{
Shifting species assemblages in the Northeast US Continental Shelf Large Marine Ecosystem
}

\author{
Sean M. Lucey* , Janet A. Nye \\ National Marine Fisheries Service, Northeast Fisheries Science Center, Woods Hole Laboratory, 166 Water Street, \\ Woods Hole, Massachusetts 02543, USA
}

\begin{abstract}
The Northeast US Continental Shelf Large Marine Ecosystem (NES LME) has experienced 2 major pressures: fishing and climate. The magnitude and rate of response to these pressures are species-specific and depend on each individual species' behavior, physiology and life histories. Thus, species assemblages can be expected to change as a result of the sum of each individual species' response. In previous studies, distinct species assemblages have been identified in each of the 4 subregions by which the NES LME has traditionally been assessed: Mid-Atlantic Bight (MAB), Southern New England (SNE), Georges Bank (GB), and Gulf of Maine (GOM). In this study, we confirm that each subregion has a distinct species assemblage, but found that those assemblages are shifting over time. The shift appears to be towards species that prefer warmer water. The result is a species assemblage within each subregion that more closely resembles the historic assemblage found in the adjacent subregion to the south. These shifts have occurred in response to a combination of both fishing and climate, and are highly nonlinear. Therefore, current reductions in fishing pressure may not be adequate to return the system to a more historic species assemblage.
\end{abstract}

KEY WORDS: Species distribution - Northeast US Continental Shelf Large Marine Ecosystem • Fishing pressure $\cdot$ Climate effect $\cdot$ Non-metric multidimensional scaling $\cdot$ ANOSIM $\cdot$ SIMPER

\section{INTRODUCTION}

Many of the world's fisheries are in the process of rebuilding from historical overfishing (Worm et al. 2009). This is a complex task as marine ecosystems are subject to a variety of pressures. Two major pressures that are being explored by the fisheries literature are fishing and climate. Fishing affects the relative biomass of species and can modify competition between them (Fogarty \& Murawski 1998, Garrison \& Link 2000, Worm \& Myers 2003), while climate stressors can fundamentally shift the distribution of species (Murawski 1993, Perry et al. 2005, Rose 2005, Nye et al. 2009). While there are many studies on species- or stock-specific responses to these 2 pressures, species assemblages within an ecosystem are molded by complex interactions among multiple stressors (Planque et al. 2010). As we continue to rebuild stocks, we must keep in mind that current environmental conditions could hinder rebuilding efforts despite the reduction in fishing effort (Hutchings 2001, Choi et al. 2005, Frank et al. 2005).

The Northeast US Large Marine Ecosystem (NES LME) has undergone considerable changes in the last 45 yr due to both fishing and environmental processes. Fish stocks were rapidly depleted first by foreign fleets and then by industrialization of the domestic fishing fleet (Fogarty \& Murawski 1998). There have been a number of management strategies to stem overfishing including reduction of fishing mortality in many stocks and the establishment of large closed areas in and around Georges Bank (GB) and the Gulf of Maine (GOM). Meanwhile, it is estimated that the temperature of the NES LME has increased by $0.23^{\circ} \mathrm{C}$ from 1982 to 2006 (Belkin 2009). Other regional studies have shown that warmer periods have occurred in the past, but unique to the recent warming is an increase in the range between the winter minimum and summer 
maximum sea surface temperatures (SSTs) (Friedland \& Hare 2007). Other climate indices point to recent large-scale warming and changes in the circulation patterns in the NES LME. The Atlantic multi-decadal oscillation (AMO) has increased over the last $40 \mathrm{yr}$ (Enfield et al. 2001, Sutton \& Hodson 2007) and the winter index of the North Atlantic oscillation (NAO) has been in a positive phase in all but 5 of the last 20 yr (Ecosystem Assessment Program 2009, Hurrell \& Deser 2009).

Numerous previous studies have examined the responses of individual species to these pressures, but few studies have examined responses at higher levels of ecological organization. Given the large changes in fishing and climate, the species assemblages of the NES LME have likely changed. The persistence of species assemblages in this region have been studied in the past (Overholtz \& Tyler 1985, Gabriel 1992, Mahon et al. 1998). These studies identified persistent fish communities but the borders between these species assemblages move from year to year, presumably due to shifting oceanic fronts. Since these studies were published, many fish species have been put under rebuilding plans (Brodziak et al. 2008). Some fish stocks, such as haddock Melanogrammus aeglefinus (Brodziak et al. 2008), have recovered, while others such as the Atlantic cod Gadus morhua have not (Rosenberg et al. 2006). Trophic interactions and ecosystem-level processes have been implicated to explain the lack of recovery in some species, highlighting the need for an analysis of temporal change in species assemblages.

This study examined the temporal change in species assemblages within 4 historic subregions of the NES LME (Clark \& Brown 1977). Clark \& Brown (1977) designated these 4 subregions as the Middle Atlantic, Southern New England, GB, and the GoM based on faunal assemblages as well as exploitation patterns and data availability. We examined the trends in the species assemblages and how they correlate with the 2 major pressures in the system: fishing and climate. Our approach uses spatially explicit units to examine the effects of fishing and climate rather than tracking a particular group of species.

\section{MATERIALS AND METHODS}

The study area is the NES LME, which extends from Cape Hatteras, North Carolina to the GOM (Fig. 1). We further divided the area into 4 subregions starting in the south with the Mid-Atlantic Bight (MAB), followed by Southern New England (SNE), GB, and GOM (Link et al. 2008, Ecosystem Assessment Program 2009). The MAB extends from Cape Hatteras, North Carolina to

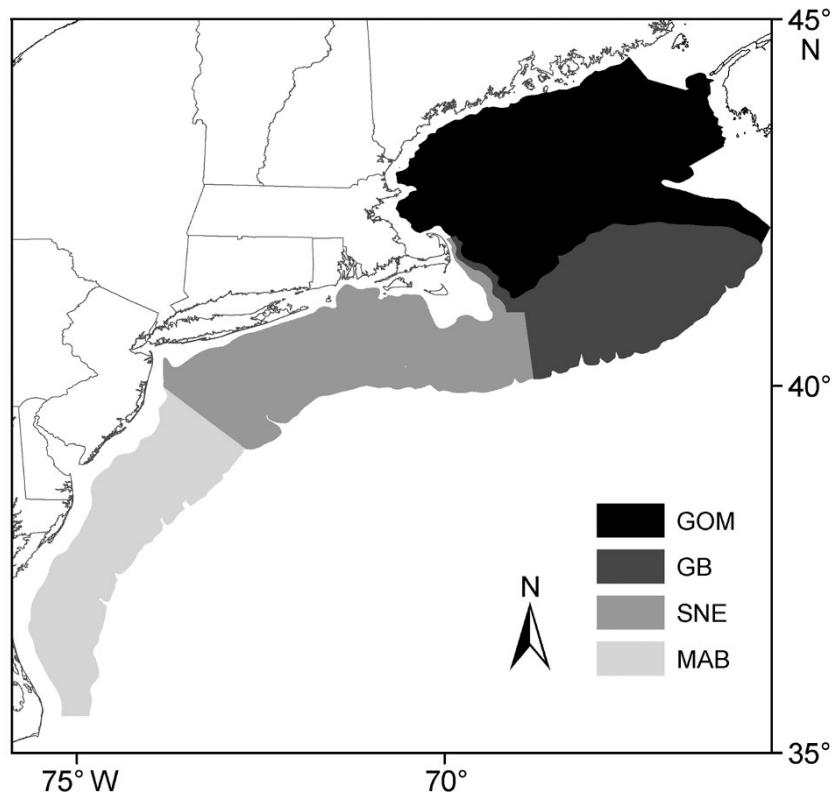

Fig. 1. The Northeast US Large Marine Ecosystem broken down into 4 subregions: Mid-Atlantic Bight (MAB), Southern New England (SNE), Georges Bank (GB), and Gulf of Maine (GOM)

Hudson Canyon off the coast of New Jersey and SNE extends from Hudson Canyon to the Great South Channel. GB is a submarine plateau due East of Cape Cod, Massachusetts and extends from the Great South Channel to the Northeast Channel. Finally, GOM is a deep cold-water basin north of GB that extends from the Great South Channel to the Bay of Fundy and Nova Scotia. All 4 areas have distinct geological, hydrological, and biological characteristics that delineate them as subregions (Clark \& Brown 1977).

Annual stratified mean biomasses per tow were obtained for each of the 50 species with the highest biomass caught during the Northeast Fisheries Science Center (NEFSC) autumn and spring bottom trawl surveys. The NEFSC autumn bottom trawl survey has operated within the NES LME since 1963, although sampling of MAB did not start until 1967. The spring bottom trawl survey has operated throughout the study area since 1968. Both surveys have an identical stratified random design whereby all fish and many invertebrate species are weighed and measured (Azarovitz 1981, NEFC 1988). We only used data from offshore strata that were sampled in every year of the surveys. The 50 species chosen for this study represent a wide range of taxonomic groups and life histories (Table 1) and account for $94.29 \% \quad(95.08 \%$ spring, $93.53 \%$ autumn) of the total biomass captured during the time series.

The species assemblage for each subregion by year was determined using a Bray-Curtis similarity index of 
the 50 species (Bray \& Curtis 1957). The Bray-Curtis index has been used in a wide range of ecological studies for its theoretical and practical applications (Clarke 1993). Among its other properties is its insensitivity to joint absences; species that are absent from both samples do not count towards the similarity of the samples (Clarke et al. 2006). The stratified mean biomass of each species was square root transformed to create a balance between common and rare species (Field et al. 1982).

Table 1. Top 50 species caught during the Northeast Fisheries Science Center's spring and autumn bottom trawl survey

\begin{tabular}{|c|c|c|c|c|c|}
\hline \multirow[t]{2}{*}{ Common name } & \multirow[t]{2}{*}{ Scientific name } & \multicolumn{3}{|c|}{ Avg biomass $\mathrm{yr}^{-1}(\mathrm{~kg})$} & \multirow[t]{2}{*}{ Preferred temp } \\
\hline & & Total & Spring & Autumn & \\
\hline \multicolumn{6}{|l|}{ Pelagic } \\
\hline Spiny dogfish & Squalus acanthias & 70450.8 & 41944.1 & 28506.7 & 8.9 \\
\hline Silver hake & Merluccius bilinearis & 5266.4 & 3217.6 & 2048.7 & 8.3 \\
\hline Longfin squid & Loligo pealeii & 4509.3 & 1499.4 & 3009.9 & 14.6 \\
\hline Butterfish & Peprilus triacanthus & 4299.9 & 1153.0 & 3147.0 & 12.6 \\
\hline Pollock & Pollachius virens & 3547.4 & 1880.1 & 1667.3 & 7.0 \\
\hline Shortfin squid & Illex illecebrosus & 2222.2 & 46.5 & 2175.6 & 10.0 \\
\hline Atlantic mackerel & Scomber scombrus & 1896.9 & 1737.4 & 159.5 & 8.0 \\
\hline Atlantic herring & Clupea harengus & 1817.5 & 1239.5 & 577.9 & 6.4 \\
\hline Weakfish & Cynoscion regalis & 1517.6 & 411.2 & 1106.4 & 18.7 \\
\hline Bluefish & Pomatomus saltatrix & 984.0 & 56.0 & 928.0 & 16.8 \\
\hline Alewife & Alosa pseudoharengus & 911.8 & 771.9 & 139.9 & 7.2 \\
\hline Bay anchovy & Anchoa mitchilli & 735.9 & 125.3 & 610.6 & 15.5 \\
\hline Round herring & Etrumeus regia & 683.5 & 40.1 & 643.4 & 15.6 \\
\hline Striped anchovy & Anchoa hepsetus & 625.2 & 25.0 & 600.3 & 12.1 \\
\hline \multicolumn{6}{|l|}{ Demersal } \\
\hline Haddock & Melanogrammus aeglefinus & 11770.9 & 5429.0 & 6341.9 & 6.7 \\
\hline Atlantic cod & Gadus morhua & 9031.8 & 5138.4 & 3893.4 & 6.6 \\
\hline Winter skate & Leucoraja ocellata & 7032.3 & 3212.2 & 3820.2 & 8.5 \\
\hline Acadian redfish & Sebastes fasciatus & 6887.1 & 3481.9 & 3405.2 & 6.8 \\
\hline Little skate & Leucoraja erinacea & 6594.5 & 4667.8 & 1926.6 & 8.0 \\
\hline Smooth dogfish & Mustelus canis & 4653.1 & 2145.6 & 2507.5 & 15.5 \\
\hline Atlantic croaker & Micropogonias undulatus & 3821.7 & 387.1 & 3434.6 & 19.8 \\
\hline White hake & Urophycis tenuis & 3731.6 & 1705.6 & 2026.0 & 7.6 \\
\hline Goosefish & Lophius americanus & 3616.3 & 2294.2 & 1322.1 & 11.1 \\
\hline Spot & Leiostomus xanthurus & 3238.8 & 559.9 & 2678.9 & 21.5 \\
\hline Red hake & Urophycis chuss & 2815.2 & 1469.6 & 1345.6 & 8.0 \\
\hline Thorny skate & Amblyraja radiata & 2447.2 & 1044.5 & 1402.7 & 6.6 \\
\hline Yellowtail flounder & Limanda ferruginea & 2395.5 & 1305.6 & 1089.9 & 7.4 \\
\hline Winter flounder & Pseudopleuronectes americanus & 2377.1 & 1300.6 & 1076.5 & 8.0 \\
\hline Scup & Stenotomus chrysops & 2230.9 & 855.5 & 1375.4 & 14.5 \\
\hline American plaice & Hippoglossoides platessoides & 2104.2 & 1055.4 & 1048.8 & 6.2 \\
\hline Northern searobin & Prionotus carolinus & 2084.1 & 1596.2 & 487.9 & 13.2 \\
\hline Windowpane flounder & Scophthalmus aquosus & 1702.2 & 1028.4 & 673.8 & 9.3 \\
\hline Ocean pout & Zoarces americanus & 1638.9 & 1487.8 & 151.1 & 5.4 \\
\hline Longhorn sculpin & Myoxocephalus octodecemspinosus & 1621.4 & 835.5 & 785.9 & 7.1 \\
\hline Roughtail stingray & Dasyatis centroura & 1534.0 & 273.6 & 1260.4 & 19.1 \\
\hline American lobster & Homarus americanus & 1360.4 & 574.4 & 786.0 & 9.4 \\
\hline Bluntnose ray & Dasyatis say & 1117.3 & 222.2 & 895.1 & 20.7 \\
\hline Horseshoe crab & Limulus polyphemus & 997.6 & 587.3 & 410.2 & 13.3 \\
\hline Fourspot flounder & Hippoglossina oblonga & 985.8 & 615.5 & 370.3 & 9.8 \\
\hline Spiny butterfly ray & Gymnura altavela & 970.8 & 183.5 & 787.3 & 21.2 \\
\hline Summer flounder & Paralichthys dentatus & 955.4 & 360.5 & 595.0 & 12.4 \\
\hline Atlantic sea scallop & Placopecten magellanicus & 937.7 & 385.6 & 552.1 & 8.8 \\
\hline Witch flounder & Glyptocephalus cynoglossus & 918.6 & 517.4 & 401.2 & 6.9 \\
\hline Spotted hake & Urophycis regia & 838.7 & 310.0 & 528.7 & 11.5 \\
\hline Sea raven & Hemitripterus americanus & 797.6 & 475.3 & 322.3 & 6.9 \\
\hline Wolffish & Anarchichas lupus & 695.2 & 556.9 & 138.3 & 5.6 \\
\hline Bullnose ray & Myliobatis freminvillii & 692.3 & 176.8 & 515.5 & 21.1 \\
\hline Cusk & Brosme brosme & 611.0 & 345.7 & 265.3 & 6.8 \\
\hline Northern sand lance & Ammodytes dubius & 512.4 & 443.2 & 69.2 & 6.8 \\
\hline Clearnose skate & Raja eglanteria & 493.0 & 276.4 & 216.6 & 12.3 \\
\hline
\end{tabular}


Temporal trends within and among the subregions were examined. The spring and autumn surveys were compared using the Spearman rank correlation coefficient $(\rho)$ between similarity matrices to check for a shared temporal trend. Next, the similarity matrices were plotted in a 2-dimensional multivariate space with non-metric multidimensional scaling (MDS) (Field et al. 1982, Clarke 1993). The ordinations were created with the software package PRIMER (version 6.1.11, PRIMER-E).

Several analytical techniques within the PRIMER software were used to further investigate the trends in the species assemblages. An analysis of similarities (ANOSIM) was used to test for significant shifts within individual subregions as well as between subregions (Clarke 1993). ANOSIM uses a priori groups to calculate within and between group ranked dissimilarities. We used the subregions as well as decades within subregions as our a priori groups. ANOSIM then tests for significance via permutations. Interactions between adjacent subregions were compared using similarity percentages (SIMPER) (Clarke 1993). SIMPER determines how similar a group is to itself as well as how dissimilar 2 groups are to each other. Similarities among subregions were compared in 3 different ways to understand the temporal shifts in species assemblages. First, adjacent subregions were compared over the entire time series by season (spring 1968 to 2008, autumn 1963 to 2008). We then compared adjacent subregions seasonally at the beginning of the time series (1968 to 1972) and at the most recent part of the time series (2004 to 2008). Finally, we compared the current (2004 to 2008) assemblage of a subregion to the historic (1968 to 1972) species assemblage of the subregion immediately to the south.

Another way of looking for trends in the species assemblage is to use the preferred temperatures of the fish community. In order to calculate the community preferred temperature, we first had to calculate the preferred temperature of individual species. The preferred temperatures of 135 species were estimated by obtaining their mean temperature weighted by biomass over all years of sampling. Species that were rarely collected were not included in the analysis. The species-specific preferred temperatures of 34 species were compared with literature values that were available to verify the method (Scott 1982, Perry \& Smith 1994, Collie et al. 2008, Richards et al. 2008). All values of species preferred temperatures were within the reported range and mean values differed by $\leq 4^{\circ} \mathrm{C}$. Linear regressions accounting for temporal autocorrelation were used to identify statistically significant changes in mean community preferred temperature (PROC AUTOREG, SAS 9.2.1). The slopes of these linear regressions were used to quantify the change in temperature for each subregion over the entire time series.

Correlations of fishing and climate change with shifts in species assemblages were evaluated using the BIO-ENV algorithm in PRIMER (Clarke \& Ainsworth 1993). BIO-ENV is a stepwise algorithm that sequentially adds and subtracts abiotic variables from a random starting subset of variables. The test statistic is a rank correlation between a similarity matrix of abiotic variables and the species assemblage similarity matrix. The abiotic variables tested were fishing, broadscale climate, and regional climate.

Total landings were used as an indicator of fishing pressure on the NES LME. Other indicators of fishing pressure were considered, but were eliminated for several reasons. Data to enumerate fishing effort for the ecosystem such as number of hours fished or number of vessels operating within the NES LME was not available for the entire time series. Fishing mortality for target species was not available for all 50 species in this study. Additionally, fishing practices affect nontarget species via bycatch, destruction of habitat by fishing gear, or by removal of prey and/or predator species such that even a combined metric of speciesspecific fishing mortality would not adequately represent fishing pressure on the ecosystem. Landings data from 1963 to 2005 were obtained from the NAFO database for subareas 5 and 6 (www.nafo.int/fisheries/ frames/fishery.html). Additional data for US landings from 2006 to 2007 were obtained from the National Marine Fisheries, Woods Hole commercial database. These landings include all groundfish, other finfish, small pelagics, crustaceans, and mollusks.

Broadscale climate variables were reduced to one representative time series using minimum-maximum autocorrelation factor analysis (MAFA). MAFA is similar to principal component analysis but maximizes the first-order autocorrelation in the composite series (Zuur et al. 2007). The primary axis of MAFA represents the strongest overall trend. The suite of environmental variables used included the extended reconstructed sea surface temperature (ERSST), NAO, AMO, wind stress, and the position of the north wall of the Gulf Stream. ERSST uses satellite data and historical in situ data to create a global SST analysis that is consistent over time (Smith \& Reynolds 2004). NAO is the difference in sea-level pressure between the Azores and Iceland (Hurrell 1995) and AMO shows the detrended anomalies in annual SST (Enfield et al. 2001). Wind stress was computed using the method of Large \& Pond (1981) and the number of 'wind events' $>12 \mathrm{~m} \mathrm{~s}^{-1}$ in each year was used in our statistical analyses. Data were obtained from National Centers for Environmental Prediction (NCEP) files recorded from 4 points in the GB/GOM region. The position of the 
north wall of the Gulf Stream is the leading spatial empirical orthogonal function (EOF) of the $15^{\circ} \mathrm{C}$ isotherm at $200 \mathrm{~m}$ calculated by Joyce et al. (2000, 2009). A positive value indicates a more northerly position of the Gulf Stream and is associated with changes in storm tracks and water temperatures on the continental shelf (Joyce et al. 2009).

Regional climate was represented by stratified mean bottom temperature calculated for each subregion using environmental data collected during the surveys. Bottom temperature provides a snapshot of the conditions being experienced by the species assemblage at the time of collection. All variables were normalized (mean subtracted and divided by the SD) before BIOENV was run.

\section{RESULTS}

The species assemblages of the spring and autumn surveys shifted over time. However, the similarity matrices were significantly correlated $(\rho=0.854, p<$ 0.001 ) indicating that similar shifts in species assemblages occurred in both seasons. Ordination of the species data showed an overall trend of subregions shifting towards species assemblages that are more like the historic assemblages found in the adjacent subregion to the south (Fig. 2). This pattern was most noticeable in the autumn data (Fig. 2d). The major exception was in GB in the spring where the species assemblage since 1999 has become more dissimilar from the species assemblage of SNE, and appears to be returning to the historical assemblage found in GB in the 1960s (Fig. 2c). The MAB was the most variable of the subregions, while GOM was the least variable (Fig. 2).

Even with the shared temporal pattern, the assemblages were more similar within than among the historical subregions as indicated by ANOSIM (Table 2). There was also a seasonal component to the species assemblages within each subregion. The species assemblage of MAB remained relatively consistent over the autumn time series $(\mathrm{R}=0.292)$, but was more dissimilar in the spring $(R=0.522)$. Similarly, but to a lesser extent, the SNE assemblage was more similar in the autumn than in the spring. Perhaps because of more consistent MAB and SNE autumn assemblages, the SNE and MAB assemblages were much more distinctive from each other in the autumn than in the spring.
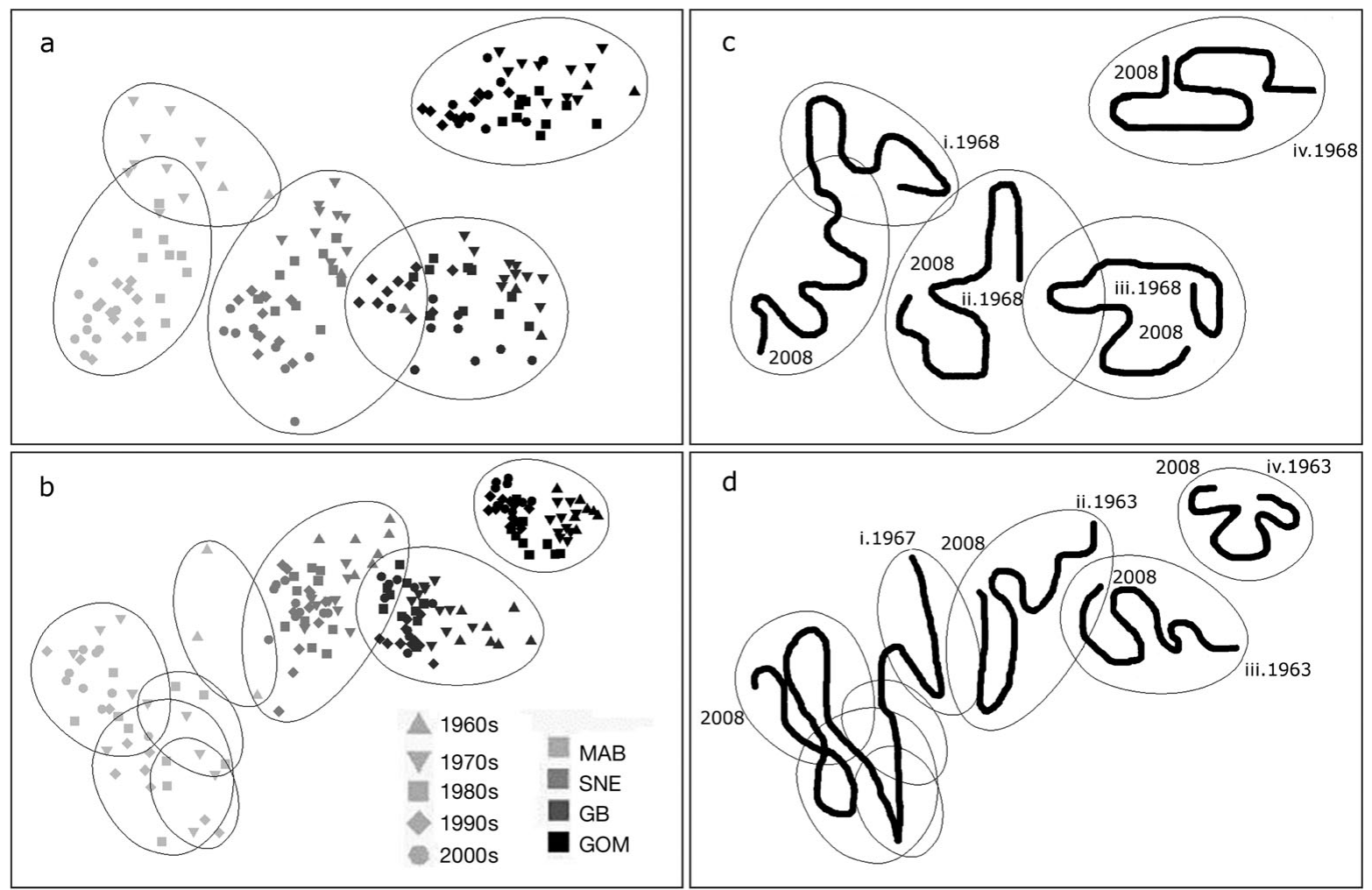

Fig. 2. Non-metric multidimensional scaling (MDS) ordination of the (a) spring and (b) autumn species assemblages based on the Bray-Curtis similarity index of square root transformed stratified mean biomass of the top 50 species. Contours enclose samples that are $60 \%$ similar based on cluster analysis. Simplified MDS shows the basic trajectory of the time series by subregion for (c) spring and (d) autumn. For the simplified trajectories, the subregions are represented as (i) MAB, (ii) SNE, (iii) GB, and (iv) GOM 
Table 2. ANOSIM by subregion. R statistics were significant at the 0.001 level for all regions. R statistics comparing a subregion to itself refers to the shift in species assemblage by decade within the subregion. An $\mathrm{R}$ value of 1.0 indicates that 2 samples are completely different, while a score of 0.0 indicates that the samples are identical. The global R statistic for the entire Northeast US Continental Shelf Large Marine Ecosystem (NES LME) was 0.912 in spring and 0.908 in autumn. Abbreviations as in Fig. 1

\begin{tabular}{|lcccc|}
\hline & MAB & SNE & GB & GOM \\
\hline Spring & & & & \\
MAB & 0.522 & 0.672 & 0.982 & 0.999 \\
SNE & & 0.666 & 0.832 & 0.995 \\
GB & & & 0.674 & 0.993 \\
GOM & & & & 0.682 \\
Autumn & & & & \\
MAB & 0.292 & 0.910 & 0.996 & 1.000 \\
SNE & & 0.485 & 0.819 & 0.995 \\
GB & & & 0.690 & 0.992 \\
GOM & & & & 0.718 \\
\hline
\end{tabular}

Table 3. ANOSIM within each subregion by decade. R statistics shown are significant at the 0.001 level. Spring sampling was not initiated until 1968 in all regions and autumn sampling in the MAB was not started until 1967; therefore, no attempt is made to include seasonal/regional comparisons. An $R$ value of 1.0 indicates that 2 samples are completely different, while a score of 0.0 indicates that the samples are identical. Abbreviations as in Fig. 1

\begin{tabular}{|c|c|c|c|c|}
\hline & $60 / 70$ & $70 / 80$ & $80 / 90$ & $90 / 00$ \\
\hline \multicolumn{5}{|l|}{ Spring } \\
\hline MAB & & 0.479 & 0.429 & \\
\hline SNE & & 0.374 & 0.543 & \\
\hline GB & & & 0.534 & 0.644 \\
\hline GOM & & & 0.570 & 0.545 \\
\hline \multicolumn{5}{|c|}{ Autumn } \\
\hline MAB & & & & \\
\hline SNE & 0.693 & 0.210 & & \\
\hline GB & 0.521 & 0.541 & 0.586 & 0.592 \\
\hline GOM & & & 0.423 & 0.560 \\
\hline
\end{tabular}

ANOSIM also provided a statistical basis for comparison of the differences within subregions over time (Table 3). GB was the only subregion to experience a significant shift in the autumn every decade. The 2 northernmost subregions (GB and GOM) saw significant changes during both seasons since the 1980s. There were no statistically significant shifts in the autumn MAB assemblage. All subregions experienced a shift in the spring assemblage between the 1980s and 1990s. However, the MAB and SNE were the only subregions to experience a decadal shift during the spring between the 1970s and 1980s.

SIMPER between adjacent subregions indicate directionality in the temporal shift in species assem-

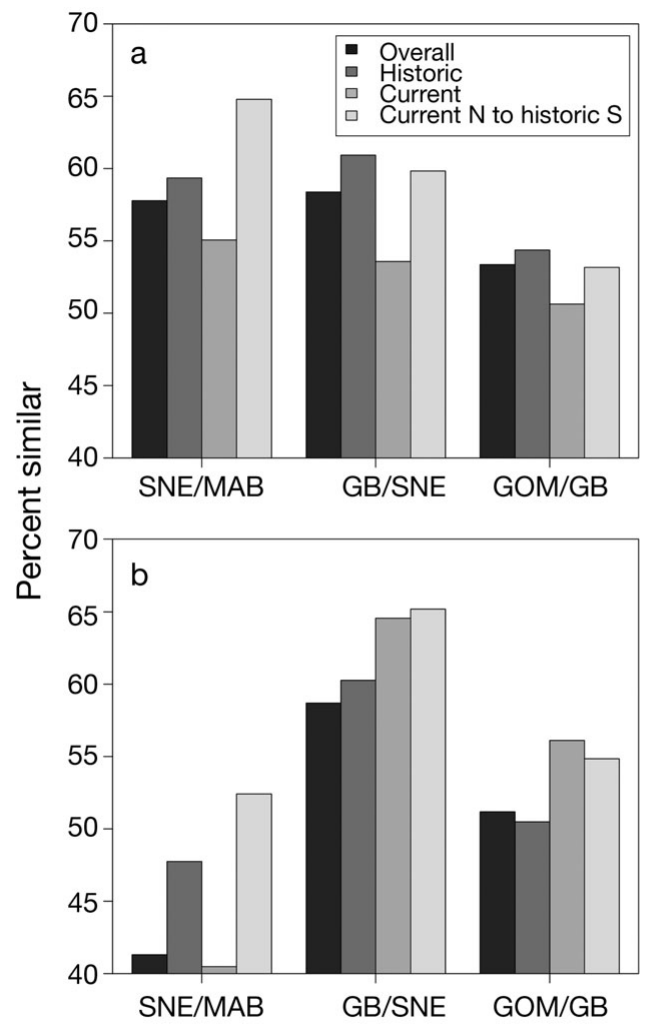

Fig. 3. SIMPER by subregion for the (a) spring and (b) autumn assemblages. Bars represent the percent similarity of the groups to each other. 'Overall': similarity over the entire time series. 'Historic': 5 yr time period at the beginning of the survey (1968-1972); 'Current': time period from 2004 to 2008. 'Current $\mathrm{N}$ to Historic $\mathrm{S}$ ': the similarity of the more northern subregion (2004 to 2008) to the southern subregion (1968 to 1972). GOM is the most northerly subregion followed by GB, and SNE, with MAB being the most southerly subregion (Fig. 1)

blages. In the spring, all adjacent subregions were more similar to each other historically than they are currently (Fig. 3). In the autumn, the same trend was observed as in the spring when comparing the MAB and SNE, but the other adjacent subregions appeared to be less similar historically than currently. In both seasons, the current species assemblage of a subregion was more similar to the historic species assemblage of its adjacent southern subregion than to the 2 subregions' similarity over the course of the overall time series. The lone exception is the spring GOM assemblage.

Community preferred temperatures increased in all subregions for both the spring and autumn (Fig. 4). This increase means that the species assemblages within all subregions shifted to species with warmer water temperature preferences. Linear trends were statistically significant for all regions in the autumn except for MAB. In the spring, the only linear trend that was statistically significant was in the GOM 


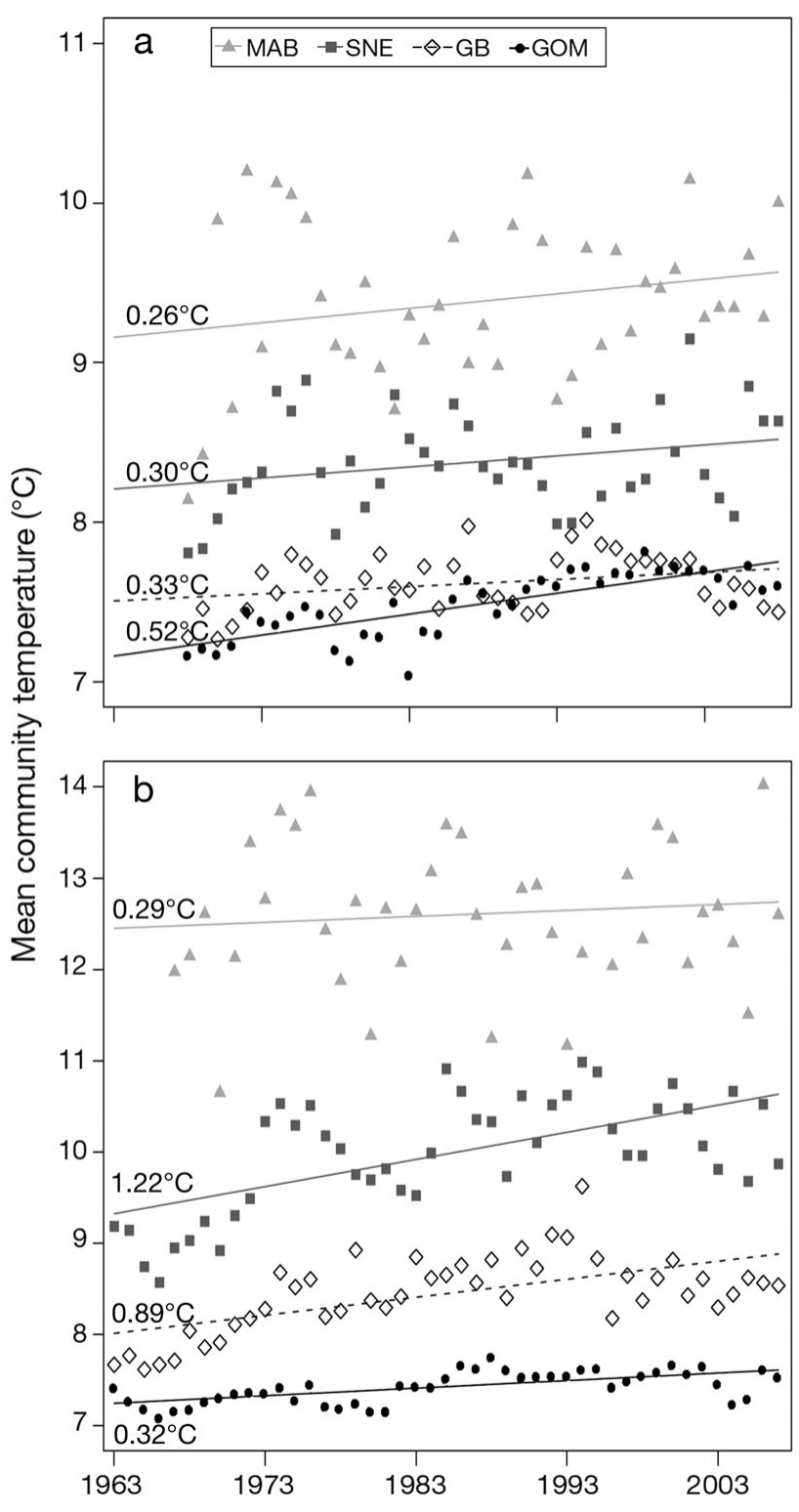

Fig. 4. Temporal trends in community preferred temperature in the (a) spring and (b) autumn for each of the 4 subregions. Numbers on the left indicate the increase in temperature over the length of the time series

assemblage. In both seasons, the highest variability in this metric was in MAB. The magnitude of change in community preferred temperature over the entire time series ranged from 0.18 to $1.34^{\circ} \mathrm{C}$.

To explain the trends in species assemblages, several broadscale climate variables were reduced into a multivariate trend with MAFA. All of the individual variables were positively loaded on the first axis (MAFA1), which represents the dominant trend with the highest autocorrelation in environmental variables (Fig. 5). In general, there was an increasing trend in all of these variables over the survey time series. This increasing trend was most highly correlated with the position of the Gulf Stream and the AMO (Fig. 5b).

Fishing pressure and a more regional measure of environmental conditions (stratified mean bottom temperature) were also used to explain the trends. Total landings were used as an indicator of fishing pressure. Landings peaked in the mid 1970s after which there was a general decreasing trend (Fig. 6). Stratified mean bottom temperature, which has generally increased over time, is representative of the conditions experienced by the assemblages at the time of sampling (Fig. 7).

Results from BIO-ENV showed strong correlations of the species assemblage similarity matrix with MAFA1 and total landings (Table 4). For the majority of the subregion/season combinations, MAFA1 showed the strongest correlation. Landings had the strongest correlation within $\mathrm{MAB}$ and SNE during the spring survey. In all cases, except for the MAB and SNE autumn assemblages, there was a stronger correlation when fishing and climatic factors were combined. During the spring survey, the combination of total landings and MAFA1 showed the strongest correlation. Stratified bottom temperature played a role in the combined effect for 3 of the 4 subregions in the autumn.

\section{DISCUSSION}

Species assemblages within the 4 historic subregions of the NES LME have shifted over time as more southerly species have become more common in northern subregions. The result is that the current assemblage in each subregion is more similar to the historic species assemblage of the adjacent southern subregion. These shifts have occurred due to both fishing and climate, and the complex interactions between these 2 pressures may render return to historical ecosystem states difficult. Furthermore, the nonlinear trajectories of community assemblage shift suggest that it may be difficult for the ecosystems to return to species assemblages that existed in the late 1960s and early 1970s. Although landings have generally decreased since the $1970 \mathrm{~s}$, current climatic conditions may prevent a return to historic species assemblages.

This shift towards more warm-water assemblages is also evident in the mean preferred temperature of the fish community. Mean preferred temperature of the community can be seen as an indicator of 2 processes: (1) an increase in the biomass of more warm-water species and/or (2) a change in the species assemblage via a change in the spatial distribution of fish stocks. The recent trend in the NES LME indicates that the fish community has shifted such that warm-temperature species are more abundant than cold-water spe- 

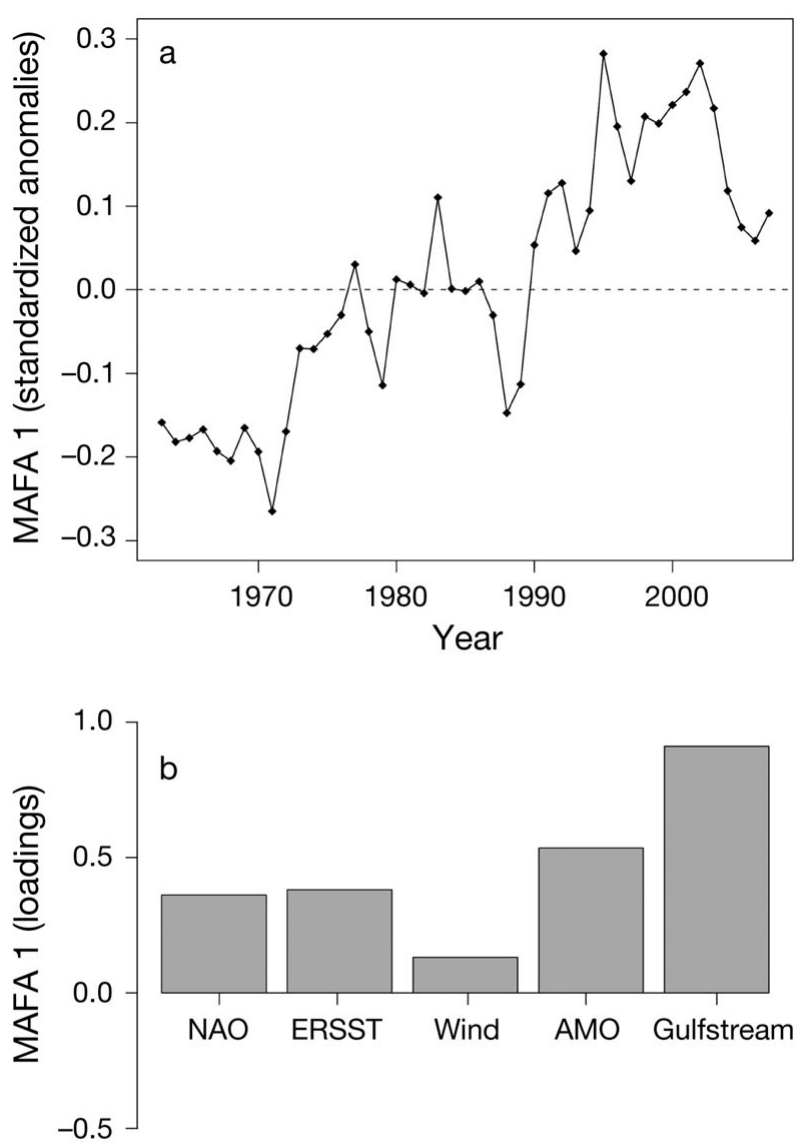

Fig. 5. Trends in environmental indicators extracted from 5 environmental variables using minimum-maximum autocorrelation factor analysis (MAFA). (a) Values of primary axis identified by MAFA. (b) Loading (canonical correlations) with the first axis identified by MAFA. NAO: North Atlantic oscillation; ERSST: extended reconstructed sea surface temperature; wind: number of wind events; AMO: Atlantic multidecadal oscillation; Gulfstream: location of the north wall of the Gulfstream

cies in recent time periods. The shift in biomass of warm-water species was more pronounced in the autumn assemblage analysis, where we also saw increases in stratified mean bottom temperature. We suspect that this may be a result of higher temperatures and longer summers in more recent times based on analysis of SST trends for the NES LME (Friedland \& Hare 2007).

The increase in mean community preferred temperature reflects the biotic response to a change in water temperature. Similar to direct measurements of water temperature for the NES LME, the mean preferred temperature of the fish community has increased in all subregions by 0.18 to $1.34^{\circ} \mathrm{C}$ over the time series except in MAB. Global mean SST has increased by $0.67^{\circ} \mathrm{C}$ over the last century (Trenberth et al. 2007) and estimates of temperature increases in the NES LME

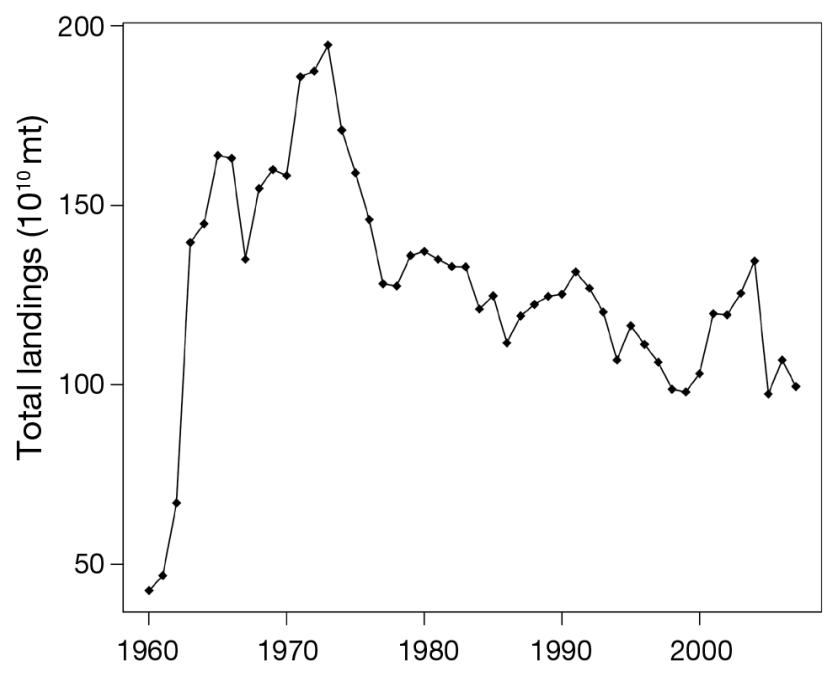

Fig. 6. Time series of total landings for the NES LME

Table 4. BIO-ENV. Values are the rank correlations between the abiotic variable and the species assemblage similarity matrix. MAFA1: primary axis value from the minimum-maximum autocorrelation factor analysis and represents the increasing trend in multiple climate indices. Landings: total landings for the NES LME. BT: stratified mean bottom temperatures from the surveys. Combination: the abiotic variables (listed in parentheses) with the highest rank correlation when combined. All variables were normalized before the algorithm was run. All values reported are significant at $p=0.001$; unreported values are not significant. Abbreviations as in Fig. 1

\begin{tabular}{|lllll|}
\hline \multicolumn{5}{r|}{ Landings } \\
\hline Spring & & & & Combination \\
MAB & 0.526 & 0.369 & 0.044 & 0.534 (landings/MAFA1) \\
SNE & 0.396 & 0.357 & 0.154 & 0.446 (landings/MAFA1) \\
GB & 0.236 & 0.296 & 0.026 & 0.330 (landings/MAFA1) \\
GOM & 0.394 & 0.451 & 0.050 & 0.492 (landings/MAFA1) \\
Autumn & & & & \\
MAB & & 0.287 & 0.201 & 0.369 (MAFA1/BT) \\
SNE & 0.260 & 0.404 & 0.187 & 0.397 (MAFA1/BT) \\
GB & 0.226 & 0.337 & 0.280 & 0.414 (all 3) \\
GOM & 0.329 & 0.415 & 0.075 & 0.434 (landings/MAFA1) \\
\hline
\end{tabular}

have ranged from $0.23^{\circ} \mathrm{C}$ since 1982 (Belkin 2009) to $\sim 1{ }^{\circ} \mathrm{C}$ since the 1960s (Friedland \& Hare 2007).

The species assemblage within MAB is the most variable of the 4 subregions probably because mean bottom temperature here is also more variable. Because the interannual variability in environmental conditions in the MAB region is high, there was no statistically significant trend in mean community temperature and no statistical shift in the autumn assemblage when analyzed by decade with ANOSIM. Furthermore, MAB is considered a transition region between southern and northern species. Some of the species included in this study are at the northern extent of their 


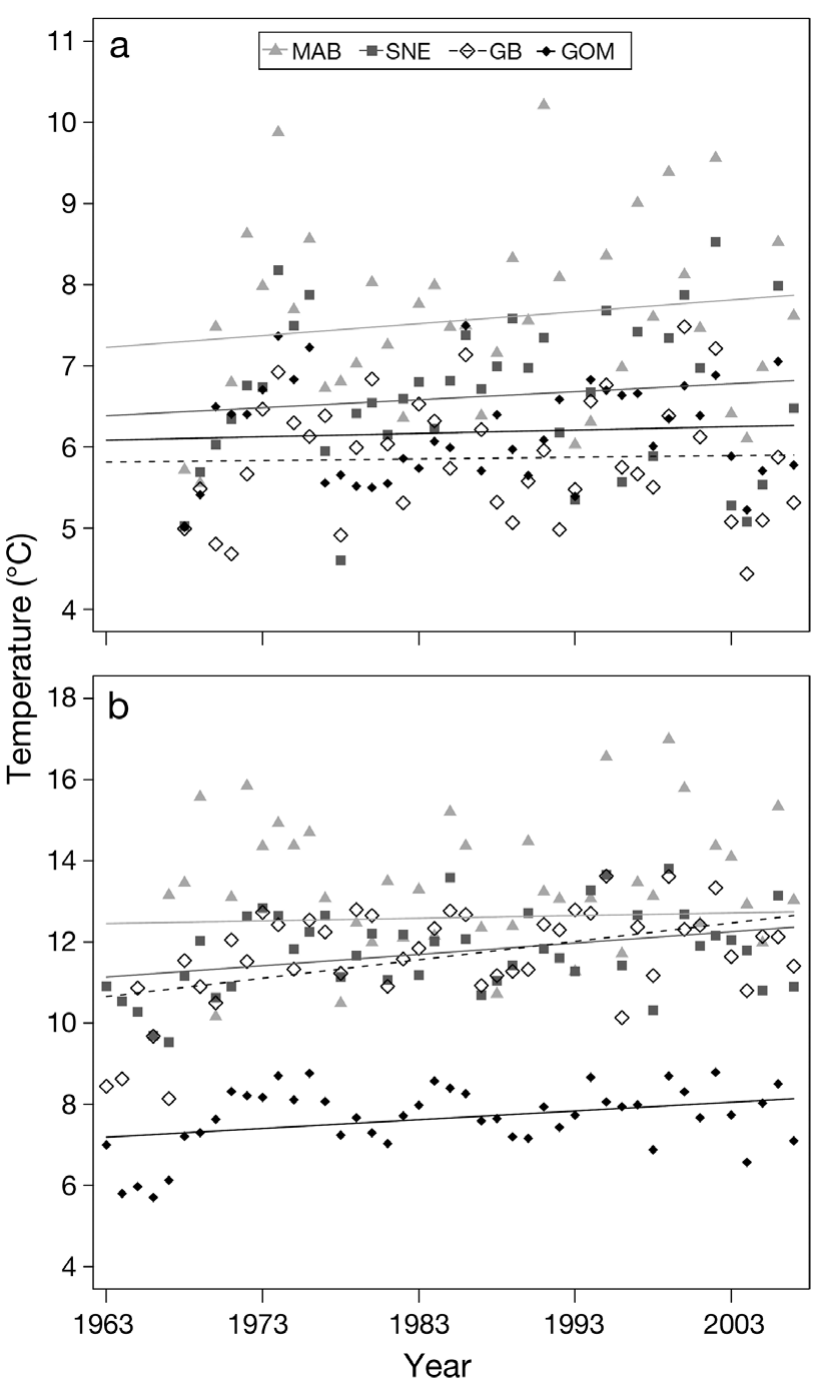

Fig. 7. Stratified mean bottom temperature during the (a) spring and (b) autumn surveys

range, while the majority of the species are at the southern extent of their range in the MAB. The presence of either group is largely determined by interannual variability in temperature (Gabriel 1992).

Conversely, GOM being the highest latitude subregion, was relatively stable in species assemblage and was most distinct from the other 3 subregions. Because of its deep waters, GOM experiences a narrower range of temperature variation than the rest of the shelf (Holzwarth \& Mountain 1990). Although temperature here was more stable than in the other subregions, the only shift in the spring community preferred temperature occurred in the GOM. The other subregions experienced increases in their community preferred temperatures but these increases were not statistically significant because of their higher variability.
This study shows that there is a strong correlation of both fishing and climate with observed trends in species assemblages. Fishing affects species assemblages primarily by changing the relative biomass of species over time (Fogarty \& Murawski 1998, Garrison \& Link 2000). Climate generally affects species assemblages by shifting spatial distributions (Perry et al. 2005, Nye et al. 2009). However, the effect of fishing on biomass and the effect of climate on spatial distribution are not mutually exclusive. Although fishing pressure has declined since its peak in the mid 1970s, many species are still considered overfished. Trends in the MDS show larger shifts in the species assemblage during the early part of the time series, when fishing was highest and increasing most rapidly. The effects of climate and fishing may interact in unexpected ways and many studies suggest that these 2 factors act synergistically such that exploited species become more sensitive to climate (Hsieh et al. 2008, Kirby et al. 2009, Planque et al. 2010). We have shown here that together, these 2 pressures have a clear effect on species assemblages and potentially on ecosystem structure. We hypothesize that the rapid increase in fishing in the early part of the time series caused an initial shift in species assemblage as indicated by the high correlation of the MDS with total landings. As landings slowly decreased, climatic factors became important in explaining the observed shifts in species assemblage. Previous analysis of species assemblages in the NES LME suggests that fishing in the northern subregions allowed migratory and temperature-responsive species to extend their ranges northward, increase their abundance, or both (Gabriel 1992).

For example, throughout the NES LME, there has been historic overfishing that has resulted in substantial declines in top predators (Fogarty \& Murawski 1998, Garrison \& Link 2000). As large piscivores and benthivores are removed from the system, the community transitions from a demersal community to a more pelagic one (Garrison \& Link 2000). This directional shift towards a more pelagic assemblage also implies that long-lived species are being replaced by shortlived ones. As temperatures continue to increase, many species exhibit a poleward shift in their distribution, with short-lived species responding more quickly (Perry et al. 2005, Nye et al. 2009). Although we have yet to observe a change in the trophic guild structure (Garrison \& Link 2000), the potential for altered trophic interactions exists.

The complexity of the combined effects of fishing and climate may make it difficult to reverse the current trajectories of the species assemblages and return to assemblages that resemble the late 1960s and early 1970s. Many of the overfished stocks within the NES LME are now under rebuilding plans (NEFSC 2008). 
Unfortunately, simply reducing the fishing pressure on a stock does not always result in an increase in biomass (Hutchings 2001, Choi et al. 2005, Frank et al. 2005). In addition to complex trophic interactions, exploited fishes may be more susceptible to climate variation than non-exploited species due to contracted geographic ranges and fishery-induced age truncation (Hsieh et al. 2008). The only species assemblage that appears to be heading towards its historic assemblage is that of GB during the spring. This is most likely due to the recovery of haddock that dominates the biomass (Brodziak et al. 2008).

In conclusion, the species assemblages of the 4 subregions of the NES LME are shifting towards a more southerly assemblage. Historic overfishing has altered the relative biomass of many species, while steadily increasing trends in climate indices correlate with shifting spatial distributions. The combined effects have resulted in an increase in community preferred temperatures. Each subregion shows a trajectory in multivariate space towards the adjacent southern subregion. As climate continues to change, we expect to see more poleward movement of species and increasing changes in trophic interactions. Even with reductions in fishing pressure that have been instituted under current rebuilding plans, the effects of climate on recovery of fish stocks may require more time for some populations and continued or increased reductions in fishing pressure. Furthermore, it may be extremely difficult for the ecosystems to return to the species assemblages of the late 1960s and early 1970s.

Acknowledgements. We thank all the scientists and crew at NEFSC who collected data over the duration of the time series; the anonymous reviewers as well as K. Friedland, J. Link, and M. Fogarty for constructive comments on earlier drafts of this manuscript; and especially B. Smith for help with PRIMER.

\section{LITERATURE CITED}

Azarovitz TR (1981) A brief historical review of the Woods Hole Laboratory trawl survey time series. Publ Spec Can Sci Halieut Aquat 58:62-67

Belkin IM (2009) Rapid warming of large marine ecosystems. Prog Oceanogr 81:207-213

Bray JR, Curtis JT (1957) An ordination of the upland forest communities of Southern Wisconsin. Ecol Monogr 27: 325-349

Brodziak J, Traver ML, Col LA (2008) The nascent recovery of the Georges Bank haddock stock. Fish Res 94:123-132

Choi JS, Frank KT, Petrie B, Leggett WC (2005) Integrated assessment of a large marine ecosystem: a case study of the devolution of the Eastern Scotian Shelf, Canada. Oceanogr Mar Biol Annu Rev 43:47-67

Clark SH, Brown BE (1977) Changes in biomass of finfishes and squids from the Gulf of Maine to Cape Hatteras, 1963-74, as determined from research vessel survey data. Fish Bull 75:1-21
Clarke KR (1993) Nonparametric multivariate analyses of changes in community structure. Aust J Ecol 18:117-143

Clarke KR, Ainsworth M (1993) A method of linking multivariate community structure to environmental variables. Mar Ecol Prog Ser 92:205-219

Clarke KR, Somerfield PJ, Chapman MG (2006) On resemblance measures for ecological studies, including taxonomic dissimilarities and a zero-adjusted Bray-Curtis coefficient for denuded assemblages. J Exp Mar Biol Ecol 330:55-80

> Collie JS, Wood AD, Jeffries HP (2008) Long-term shifts in the species composition of a coastal fish community. Can J Fish Aquat Sci 65:1352-1365

Ecosystem Assessment Program (2009) Ecosystem assessment report for the Northeast US Continental Shelf Large Marine Ecosystem. Ref Doc 09-11, NEFSC, Woods Hole, MA

Enfield DB, Mestas-Nunez AM, Trimble PJ (2001) The Atlantic multidecadal oscillation and its relation to rainfall and river flows in the continental US. Geophys Res Lett 28: $2077-2080$

Field JG, Clarke KR, Warwick RM (1982) A practical strategy for analyzing multispecies distribution patterns. Mar Ecol Prog Ser 8:37-52

Fogarty MJ, Murawski SA (1998) Large-scale disturbance and the structure of marine systems: fishery impacts on Georges Bank. Ecol Appl 8:S6-S22

Frank KT, Petrie B, Choi JS, Leggett WC (2005) Trophic cascades in a formerly cod-dominated ecosystem. Science 308:1621-1623

Friedland KD, Hare JA (2007) Long-term trends and regime shifts in sea surface temperature on the continental shelf of the northeast United States. Cont Shelf Res 27: 2313-2328

Gabriel WL (1992) Persistence of demersal fish assemblages between Cape Hatteras and Nova Scotia, Northwest Atlantic. J Northwest Atl Fish Sci 14:29-46

Garrison LP, Link JS (2000) Fishing effects on spatial distribution and trophic guild structure of the fish community in the Georges Bank region. ICES J Mar Sci 57:723-730

Holzwarth T, Mountain DG (1990) Surface and bottom temperature distributions from the Northeast Fisheries Center spring and fall bottom trawl survey program, 1963-1987 with addendum for 1988-1990. Ref Doc 90-03, NEFSC, Woods Hole, MA

> Hsieh CH, Reiss CS, Hewitt RP, Sugihara G (2008) Spatial analysis shows that fishing enhances the climatic sensitivity of marine fishes. Can J Fish Aquat Sci 65:947-961

Hurrell JW (1995) Decadal trends in the North Atlantic Oscillation: regional temperature and precipitation. Science 269:676-679

> Hurrell JW, Deser C (2009) North Atlantic climate variability: the role of the North Atlantic Oscillation. J Mar Syst 78: $28-41$

> Hutchings JA (2001) Influence of population decline, fishing, and spawner variability on the recovery of marine fishes. J Fish Biol 59:306-322

Joyce TM, Deser C, Spall MA (2000) The relation between decadal variability of Subtropical Mode Water and the North Atlantic Oscillation. J Clim 13:2550-2569

> Joyce TM, Kwon YO, Yu L (2009) On the relationship between synoptic wintertime atmospheric variability and path shifts in the Gulf Stream and the Kuroshio Extension. J Clim 22:3177-3192

Kirby RR, Beaugrand G, Lindley JA (2009) Synergistic effects of climate and fishing in a marine ecosystem. Ecosystems 12:548-561 
Large WG, Pond S (1981) Open ocean momentum flux measurements in moderate to strong winds. J Phys Oceanogr 11:324-336

Link J, Overholtz W, O'Reilly J, Green J and others (2008) The Northeast U.S. continental shelf Energy Modeling and Analysis exercise (EMAX): ecological network model development and basic ecosystem metrics. J Mar Syst 74: 453-474

Mahon R, Brown SK, Zwanenburg KCT, Atkinson DB and others (1998) Assemblages and biogeography of demersal fishes of the east coast of North America. Can J Fish Aquat Sci 55:1704-1738

Murawski SA (1993) Climate change and marine fish distributions: forecasting from historical analogy. Trans Am Fish Soc 122:647-658

NEFC (Northeast Fisheries Center) (1988) An evaluation of the bottom trawl survey program of the Northeast Fisheries Center. NMFS-F/NEC 52, NEFC, Woods Hole, MA

NEFSC (Northeast Fisheries Science Center) (2008) Assessment of 19 Northeast groundfish stocks through 2007. Report of the 3rd Groundfish Assessment Review Meeting (GARM III). Ref Doc 08-15, NEFSC, Woods Hole, MA

> Nye JA, Link JS, Hare JA, Overholtz WJ (2009) Changing spatial distribution of fish stocks in relation to climate and population size on the Northeast United States continental shelf. Mar Ecol Prog Ser 393:111-129

Overholtz WJ, Tyler AV (1985) Long-term responses of the demersal fish assemblages of Georges Bank. Fish Bull 83: 507-520

Perry RI, Smith SJ (1994) Identifying habitat associations of marine fishes using survey data: an application to the Northwest Atlantic. Can J Fish Aquat Sci 51:589-602

Perry AL, Low PJ, Ellis JR, Reynolds JD (2005) Climate change and distribution shifts in marine fishes. Science 308:1912-1915

Editorial responsibility: Romuald Lipcius,

Gloucester Point, Virginia, USA
Planque B, Fromentin JM, Cury PM, Drinkwater KF, Jennings S, Perry RI, Kifani S (2010) How does fishing alter marine populations and ecosystem sensitivity to climate? J Mar Syst 79:403-417

Richards RA, Nitshke PC, Sosebee KA (2008) Population biology of monkfish Lophius americanus. ICES J Mar Sci 65: 1291-1305

Rose GA (2005) On distributional responses of North Atlantic fish to climate change. ICES J Mar Sci 62:1360-1374

Rosenberg AA, Swasey JH, Bowman M (2006) Rebuilding US fisheries: progress and problems. Front Ecol Environ 4: 303-308

Scott JS (1982) Depth, temperature and salinity preferences of common fishes of the Scotian Shelf. J Northwest Atl Fish Sci 3:29-39

Smith TM, Reynolds RW (2004) Improved extended reconstruction of SST (1854-1997). J Clim 17:2466-2477

Sutton RT, Hodson DLR (2007) Climate reponse to basin-scale warming and cooling of the North Atlantic Ocean. J Clim 20:891-907

Trenberth KE, Jones PD, Ambenje P, Bojariu R and others (2007) Observations: surface and atmospheric climate change. In: Solomon S, Qin D, Manning M, Chen Z and others (eds) Climate change 2007: the physical science basis. Contribution of Working Group I to the Fourth Assessment Report of the Intergovernmental Panel on Climate Change. Cambridge University Press, Cambridge, p $235-336$

> Worm B, Myers RA (2003) Meta-analysis of cod-shrimp interactions reveals top-down control in oceanic food webs. Ecology 84:162-173

> Worm B, Hilborn R, Baum JK, Branch TA and others (2009) Rebuilding global fisheries. Science 325:578-585

Zuur AF, Ieno EN, Smith GM (2007) Analyzing ecological data. Springer Science and Business Media, New York, NY

Submitted: March 20, 2010; Accepted: July 19, 2010

Proofs received from author(s): September 10, 2009 